\title{
Review of metformin and glyburide in the management of gestational diabetes
}

\author{
Dana G. CARROLL, Kristi W. KELLEY. \\ Received (first version): 30-Oct-2014 Accepted: 3-Dec-2014
}

\begin{abstract}
${ }^{*}$
Background: Worldwide, gestational diabetes affects $15 \%$ of pregnancies. It is recommended in patients with gestational diabetes to initiate diet therapy and if this is not adequate, insulin is the next treatment modality. While insulin is the preferred drug therapy to manage gestational diabetes in the majority of women, it may not always be the best option for all women.

Objective: The purpose of this review is to assess the efficacy and safety of oral agents for treatment of gestational diabetes.

Methods: A literature search of the MEDLINE, Ovid databases and Google Scholar was performed using the search term "gestational diabetes" combined with each "metformin" and "glyburide". The time frame for the search was inception through August 2014. Randomized controlled trials and cohort (both prospective and retrospective) trials, published in English, with human participants were included. Studies included only pregnant women diagnosed with gestational diabetes.

Results: There were no significant differences in preterm deliveries, delivery modes, macrosomia, and birth weights and large for gestational age when utilizing glyburide vs insulin for gestational diabetes management. There were significantly higher neonatal intensive care unit admissions as well as longer lengths of stay for hypoglycemia and respiratory distress in babies whose mothers were treated with glyburide versus insulin. For the studies comparing metformin to insulin, there are no significant differences reported for birth weight, gestational age, delivery mode, prematurity and perinatal deaths. Women taking metformin may require supplemental insulin more frequently than those taking glyburide.

Conclusion: Glyburide and metformin appear to be safe and effective to manage blood glucose in patients with gestational diabetes who prefer to not utilize insulin or who cannot afford insulin therapy. All other oral therapies to manage blood glucose levels during gestational diabetes should be reserved until additional evidence is available regarding safety and efficacy to both mother and fetus.
\end{abstract}

Keywords: Diabetes, Gestational; Glyburide; Metformin; Insulin; Comparative Effectiveness Research; Patient Safety; Pregnancy

\section{INTRODUCTION}

Gestational diabetes occurs in 2 to $10 \%$ of pregnancies in the United States each year, and it could be as high as $18 \%$ with new screening criteria being utilized (any pregnant patient between 24 to 28 weeks should be screened, regardless of the presence or absence or risk factors). ${ }^{1,2}$ Worldwide, gestational diabetes affects $15 \%$ of pregnancies. ${ }^{3}$ With the incidence of gestational diabetes continuing to rise, providers will be challenged to provide increasing numbers of their obstetrical patients with comprehensive care to minimize complications of gestational diabetes. It is critical maternal blood glucose be controlled as there are both maternal and fetal complications associated with poor blood glucose control in patients with gestational diabetes. Maternal complications include pre-eclampsia and increased incidence of cesarean section. Fetal complications include macrosomia, shoulder dystocia or trauma in birth, hypoglycemia, hyperbilirubinemia, respiratory distress syndrome, increased incidence of congenital birth defects, spontaneous abortion, and intra-uterine fetal death. ${ }^{4}$ Mother and baby are also at higher risk long term for developing type 2 diabetes mellitus and being obese. 4

The American College of Obstetricians and Gynecologists (ACOG), International Diabetes Federation (IDF), Canadian Diabetes Association (CDA) and the National Institute for Health and Care Excellence (NICE) all currently recommend starting with diet therapy to try to achieve normal blood glucose levels in patients with gestational diabetes. $^{3-7}$ If this is not adequate, insulin is currently recommended as the next treatment modality to utilize to achieve and maintain blood glucose control by ACOG, IDF, and CDA. ${ }^{4-6}$ Only NICE recommends it as a suitable first line option alongside insulin analogs. ${ }^{7}$ Many women may not want insulin therapy for several reasons. Some do not want the hassle of numerous injections each day or may even be fearful of injecting insulin. For some, the cost of insulin therapy can be burdensome. Finally, patients and providers alike may be concerned regarding the hypoglycemia that can occur more frequently and more severely with insulin therapy. ACOG recently updated its position statement and acknowledges that oral medications, specifically glyburide or metformin, "can be considered" to lower blood glucose levels. ${ }^{4}$ Additionally, ACOG's updated position statement includes data that reflect that although glyburide crosses the placenta there has not been adverse effects in the short-term on the mother or baby.

However, they still suggest caution in
'Dana G. CARROLL. PharmD. Associate Clinical Professor. Department of Pharmacy Practice, Harrison School of Pharmacy, Auburn University. Auburn, AL (United States).dgc0001@auburn.edu Kristi W. KELLEY. PharmD. Associate Clinical Professor. Department of Pharmacy Practice, Harrison School of Pharmacy, Auburn University. Auburn, AL (United States). watsokm@auburn.edu 
communicating with patients so that they are aware that the long-term data regarding effects on mother or baby is not available. Although ACOG's position statement was updated in 2013 , it does not include all of the literature published that assess the efficacy and safety of newer and existing oral medications to manage gestational diabetes. IDF and CDA list metformin and glyburide as an alternative to insulin therapy in women who are" nonadherent or refuse insulin" 6 or "where insulin cannot be afforded or where circumstances make it hazardous to use". 5 CDA even recommends discussing utilization of these medications as they are off label uses (in gestational diabetes). ${ }^{6}$ This article will review the currently available literature regarding use of oral medications to manage gestational diabetes.

\section{METHODS}

A literature search of the MEDLINE and Ovid databases as well as Google Scholar was performed using the search term "gestational diabetes" combined with each "metformin" and "glyburide". The time frame for the search was inception through August 2014. Randomized controlled trials and cohort (both prospective and retrospective) trials, published in English, with human participants were included. Studies included only pregnant women diagnosed with gestational diabetes.

\section{LITERATURE REVIEW}

\section{Sulfonylureas and GDM}

An initial randomized, controlled trial in 404 patients with gestational diabetes compared glyburide to insulin management after dietary education. ${ }^{8}$ There were no significant differences in maternal (blood glucose control, delivery mode and pre-eclampsia) or fetal (birth weight, macrosomia, hypoglycemia, and NICU [neonatal intensive care unit] admissions) outcomes reported. Only $4 \%(n=8)$ of women on glyburide ( $\max$ dose) failed therapy and were converted to insulin.

Since this initial trial, eight additional cohort (prospective and retrospective) trials ${ }^{9-16}$ and one randomized controlled trial ${ }^{17}$ assessing glyburide in gestational diabetes have been published. Most of the trials are small [ranging from 73 to 235 patients] ${ }^{9,10,12-15,17}$; however there are two larger trials $(n=584$ and $n=10,682){ }^{11,16}$ The smaller cohort trials and randomized controlled trial reported no significant differences in patients managed with glyburide compared to insulin for maternal (delivery mode) or fetal outcomes (birth weight, dystocia, and macrosomia). 9,10,12-15,17 Two trials did report higher NICU admissions for hypoglycemia and respiratory distress in babies whose mothers were treated with glyburide versus insulin. ${ }^{8,12}$ Failure rates (requiring management with insulin) in these trials ranged from $6 \%$ to $20 \%{ }^{9,10,12-15}$ Some limitations of these studies include trial design as well, the small sample size, as well as the lack of diversity in patient populations included (many were exclusively
Hispanic populations), and lack of dosing protocols for glyburide.

The two larger trials are retrospective in design. The trial by Jacobson and colleagues ${ }^{11}[n=584]$ was a cohort comparing patients managed with glyburide $(n=316)$ to those managed with insulin $(n=268)$ The groups were similar demographically regarding age and risk factors for GDM and time to initiate therapy for GDM. There were significantly more Caucasians and fewer Asians in the insulin group. The mean dose for glyburide was $5.6 \mathrm{mg} \mathrm{SD}=4.6$ and 34.4 units $S D=28.1$ of insulin. Only 28 patients $(12 \%)$ failed glyburide therapy and were switched to insulin in the trial. There were no significant differences in delivery modes, macrosomia, and birth weights and large for gestational age. Significantly more women treated with glyburide had preeclampsia compared to those treated with insulin $(12 \%$ vs $6 \%, p=0.02)$. There were significantly more NICU admissions and longer NICU lengths of stay for babies whose mothers were treated with insulin compared to those treated with glyburide $(24 \%$ vs $15 \%, p=0.002$ and 8.0 days, $S D=10.1$ vs $4.3, S D=9.6, p=0.002$ ). The biggest limitation of this trial is its retrospective, cohort design.

The largest trial published to date assessed glyburide $(n=2,073)$ compared to insulin $(n=8,609)$ for management of GDM was conducted by Cheng and colleagues. ${ }^{16}$ There were significant differences in all demographic variables reported. Mean dosing for insulin and glyburide was not reported. Nor were failure rates to glyburide reported. There were no significant differences in preterm deliveries, macrosomia and large for gestational age. There were significantly less cesarean sections in the glyburide group $(\mathrm{OR}=0.77,95 \% \mathrm{Cl} 0.65: 0.91)$ yet significantly more NICU admissions (OR=1.46, $95 \% \mathrm{Cl} 1.07: 2.00)$ with glyburide compared to insulin. Limitations of this trial include its retrospective design and significant differences in all demographic variables between the two groups.

At this point, glyburide has the most evidence of all the sulfonylureas in the management of GDM. Many of these trials $9,13,14,16$ have examined patient characteristics and risk factors for success and failure of glyburide therapy for managing GDM. These characteristics (see Table 1) should be considered when determining if a patient may be a candidate for glyburide. If glyburide is utilized, it should be started at a low dose (2.5 to $5 \mathrm{mg}$ daily) and titrated to effect (maximum dose $20 \mathrm{mg}$ daily). The blood glucose lowering effects should be evident within 24 hours of initiation and should peak within several days. The most common adverse effect experienced with glyburide is hypoglycemia.

\section{Metformin and GDM}

An initial cohort trial assessed the use of metformin to sulfonylureas and insulin in 118 women. ${ }^{18}$ This study published in 2000 reported increased incidences of eclampsia, still births and perinatal mortality with metformin use compared to sulfonylureas and insulin. This prompted many clinicians to avoid use of metformin until additional trials were conducted to confirm or refute this risk. 


\begin{tabular}{|c|c|c|}
\hline Agent & Characteristics of ideal candidate & More likely to require supplemental insulin \\
\hline Glyburide $^{9,13,14,16}$ & $\begin{array}{l}\text { Fasting level on OGTT } 110 \mathrm{mg} / \mathrm{dL} \text { or lower } \\
\text { Later gestational age at time of treatment ( } 25 \text { or } \\
\text { more weeks) } \\
\text { Concern regarding maternal hypoglycemia } \\
\text { awareness and treatment with insulin } \\
\text { Maternal concern regarding injecting insulin } \\
\text { Singleton pregnancy }\end{array}$ & $\begin{array}{l}\text { Fasting level on OGTT } 110 \mathrm{mg} / \mathrm{dL} \text { or higher } \\
\text { Earlier gestational age at time of treatment }(<25 \\
\quad \text { weeks) } \\
\text { Older maternal age } \\
\text { Higher gravity } \\
\text { Multiparous } \\
\text { History of gestational DM } \\
\text { Lower education level ( }<9 \text { years of school) } \\
\text { English is a second language/do not speak English }\end{array}$ \\
\hline Metformin $^{20,23,25}$ & $\begin{array}{l}\text { Lower BMI at time of treatment } \\
\text { Fasting level on OGTT } 100 \mathrm{mg} / \mathrm{dL} \text { or lower } \\
\text { Later gestational age at time of treatment } \\
\text { Initial episode of gestational DM } \\
\text { Concern regarding maternal hypoglycemia } \\
\text { awareness and treatment regarding insulin or } \\
\text { glyburide } \\
\text { Maternal concern regarding injecting insulin }\end{array}$ & $\begin{array}{l}\text { Higher BMI at time of treatment ( } 35 \text { or higher) } \\
\text { Fasting level on OGTT } 110 \mathrm{mg} / \mathrm{dL} \text { or higher } \\
\text { Earlier gestational age at time of treatment } \\
\text { History of gestational DM } \\
\text { Maternal age }\end{array}$ \\
\hline
\end{tabular}

In 2007 a small $(n=63)$, randomized open label trial was conducted comparing metformin to insulin therapy who had failed dietary control. ${ }^{19}$ This trial reported no significant differences in maternal (glucose levels and delivery mode) or fetal (birth weight, gestational age at delivery, hypoglycemia and perinatal death) outcomes. However, one big limitation of this trial is only half of the patients that were needed to achieve power were enrolled.

In 2008, the MiG trial was published. ${ }^{20}$ It was a large $(n=751)$ randomized, open label trial comparing metformin to insulin. This is the largest gestational diabetes trial published to date comparing oral therapy to insulin with a primary focus on neonatal outcomes. There was no significant difference in the primary composite outcome (neonatal hypoglycemia, respiratory distress, phototherapy need, birth trauma, 5 minute APGAR score $<7$ and prematurity) between the two arms (32\% metformin vs $32.2 \%$ insulin $[p=0.95], R R=0.99,95 \% \mathrm{Cl}$ $0.8: 1.23)$. There were more incidences of neonatal severe hypoglycemia (BG levels $<28.8 \mathrm{mg} / \mathrm{dL}$ ) with insulin compared to metformin $(8.1 \%$ vs $3.3 \%$, $p=0.008)$. There was a significant increase in the number of preterm births ( $<37$ weeks gestation) with metformin compared to insulin $(12.1 \%$ vs $7.6 \%$, $p=0.04)$. However, there was minimal clinical difference in mean gestational age between the two agents, 38.3 weeks with metformin vs 38.5 weeks with insulin. Forty six percent of patients on metformin required supplemental insulin during the trial. Women who had a higher BMI and higher baseline blood glucose were more likely to require supplemental insulin in this trial.

Since MiG, nine additional metformin trials have been published. Six compare metformin to insulin ${ }^{21-}$ ${ }^{26}$ while the other three ${ }^{27-29}$ compare metformin to glyburide. All are relatively small and only three of the nine are randomized, controlled design. For all but one of the studies comparing metformin to insulin, there are no significant differences reported for birth weight, gestational age, delivery mode, prematurity and perinatal deaths. ${ }^{21-23,25,26}$ The other trial reported significantly more babies with birth weights $>90$ th percentile (vs $n=28$ [35.0\%] vs $n=14$ [17.5\%], $p=0.012$ ) and higher birth weights (mean $3.4, \mathrm{SD}=0.4$ vs3.3, $\mathrm{SD}=0.4 \mathrm{~kg}, \mathrm{p}=0.005$ ) in the insulin group compared to the metformin group. ${ }^{24}$ For the trials comparing metformin to glyburide, there were no significant differences in maternal blood glucose, neonatal hypoglycemia, macrosomia or gestational age at delivery. ${ }^{27-29}$ There were significant differences in cesarean rates $(14.6 \%$ vs $2.7 \%, p=0.02$ ) as well as the number of patients requiring insulin therapy $(34.7 \%$ vs $16.2 \%, p=0.01)$ in the metformin group compared to the glyburide group in one of the trials ${ }^{28}$, which was not found in the other two. ${ }^{27,29}$

There is additional safety data when also considering the impact of metformin on the fetus from polycystic ovary syndrome trials ${ }^{30-32}$ and type 2 diabetes trials. ${ }^{32}$ In these trials, the fetus was exposed to metformin during part of, if not all of embryogenesis, unlike gestational diabetes trials. There have been no significant differences in infants exposed to metformin regarding fetal harm in utero, at time of birth and even up to 18 months of age in these trials. ${ }^{30-33}$

Many of these trials ${ }^{20,23,25}$ have examined patient characteristics and risk factors for success and failure of metformin therapy for managing GDM. These characteristics (see Table 1) should be considered when determining if a patient may be a candidate for metformin. If metformin is to be utilized to manage gestational diabetes, the dose should be started no higher than $500 \mathrm{mg}$ twice a day to improve toleration and may be titrated to $1000 \mathrm{mg}$ twice daily after one week. The blood glucose lowering effects should be evident within 24 hours of initiation and should peak within several days. The most common adverse effects experienced with metformin are gastrointestinal in nature- diarrhea, cramping, nausea and flatulation. These are most common at initiation of therapy and with each subsequent dose adjustment. Typically these adverse effects resolve with continued use in seven to ten days. If patients are noncompliant with therapy, these adverse effects may persist longer or never completely resolve. A very small minority of patients may not be able to tolerate metformin, in spite of appropriate dose at initiation, slow dose titration, and compliance with daily administration and will have to discontinue therapy. 
along with patient specific characteristics when determining the most optimal therapy to manage blood glucose in a patient with gestational diabetes. (See Table 1) While insulin will likely remain the preferred drug therapy to manage gestational diabetes in the majority of women, it may not always be the best option for all women. Some women will be resistant to injecting insulin on a daily basis or may not be able to afford insulin. Others may not have good insight into the signs and symptoms of hypoglycemia or be able to effectively treat it in a timely manner. It will be important for prescribers to identify these women and determine if they have characteristics present (see Table 1) that may increase the success of oral therapies (glyburide or metformin) to manage blood glucose.

Based on the current evidence, metformin and glyburide appear to be safe to both mother and fetus as well as effective to manage blood glucose in patients with gestational diabetes who prefer to not utilize insulin or who cannot afford insulin therapy. All other oral therapies to manage blood glucose levels during gestational diabetes should be reserved until additional evidence is available regarding safety and efficacy to both mother and fetus (see Table 2 for summary).

Additional randomized, controlled trials that assess the optimal therapy to manage blood glucose levels with these new diagnostic criteria are needed, as these women may not have as elevated blood glucose levels as with the old diagnostic criteria. They may be at increased risk for hypoglycemia with insulin therapy if medical nutrition therapy is ineffective in attaining goal blood glucose levels. Also needed are studies that assess the long term outcomes to both mother and child in women who utilized oral blood glucose lowering agents to manage gestational diabetes. In addition, other oral antidiabetes agents (see Table 2) need to be studied to assess both efficacy and safety in gestational diabetes management for both mother and fetus.

\section{CONFLICT OF INTEREST}

We have nothing to disclose. We have no conflicts of interest. We received no financial support to write this manuscript. The views expressed in this article are our own. They are not an official position of our parent institution/employer.

\section{REVISIÓN DE LA METFORMINA Y LA GLIBURIDA EN EL MANEJO DE LA DIABETES GESTACIONAL}

\section{RESUMEN}

Antecedentes: En el mundo, la diabetes afecta al 15\% de los embarazos. Se recomienda en pacientes con diabetes gestacional que se comience con dieta $y$, si esto no es adecuado, la insulina es la siguiente modalidad de tratamiento. Aunque la insulina es la farmacoterapia preferida para el manejo de la diabetes gestacional en la mayoría de las mujeres, puede que no siempre sea la mejor opción para todas ellas.

Objetivo: El propósito de esta revisión es evaluar la eficacia y seguridad de los agentes orales para el tratamiento de diabetes gestacional.

Métodos: Se realizó una búsqueda de literatura en MEDLINE, bases de datos de Ovid y Google Scholar con el término de búsqueda "diabetes gestacional" combinado con metformina y con gliburida. El maco temporal de la búsqueda fue desde la creación hasta agosto de 2014. Se incluyeron los estudios controlados aleatorizados y de cohorte (tanto prospectivos como retrospectivos), publicados en inglés, y con participantes humanos. Los estudios incluían solo mujeres embarazadas con diabetes gestacional.

Resultados: No había diferencias en los partos pretérmino, tipos de parto, macrosomía, y pesos y alturas al nacer cuando se usaba gliburida contra insulina en el manejo de la diabetes gestacional. Hubo significativamente más ingreso en unidades neonatales de cuidados intensivos y mayores duraciones de internamiento por hipoglicemia y estrés respiratorio en recién nacidos cuyas madres fueron tratadas con gliburida contra insulina. En los estudios que comparaban metformina con insulina no hubo diferencias significativas que reportar en peso al nacer, edad gestacional, modo de parto, muertes prematuras y perinatales. Las mujeres que tomaron metformina requirieron suplementación con insulina con más frecuencia que las que tomaron gliburida.

Conclusión: La gliburida y la metformina parecen ser seguras y efectivas para manejar la glicemia en pacientes con diabetes gestacional que prefieren no utilizar insulina o que no pueden permitirse el tratamiento con insulina. Todos los otros tratamientos orales para gestión de la glicemia durante la diabetes gestacional deberían reservarse hasta que esté disponible más evidencia sobre su seguridad y eficacia para la madre y el feto.

Palabras clave: Diabetes Gestacional; Gliburida; Metformina; Insulina; Investigación sobre la Eficacia Comparativa; Seguridad del Paciente; Embarazo

\section{References}

1. National Diabetes Statistics 2011. National Institutes of Health. Available at: http://www.diabetes.niddk.nih.gov/dm/pubs/statistics/\#Gestational (accessed June 26, 2013).

2. American Diabetes Association. Standards of medical care in Diabetes-2014. Diabetes Care. 2014;37(Suppl 1):S14S80. doi: $10.2337 / \mathrm{dc} 14-\mathrm{S} 014$

3. Gestational Diabetes. Internal Diabetes Federation. http://www.idf.org/gestational diabetes (accessed September 22, 2014).

4. Committee on Practice Bulletins--Obstetrics.Practice Bulletin No. 137: Gestational diabetes mellitus. Obstet Gynecol. 2013;122(2 Pt 1):406-416. doi: 10.1097/01.AOG.0000433006.09219.f1

5. Pregnancy and Diabetes. International Diabetes Federation. http://www.idf.org/webdata/docs/Pregnancy EN RTP.pdf (accessed September 22, 2014).

6. Diabetes and Pregnancy. Canadian Diabetes Association Clinical Practice Guidelines. http://guidelines.diabetes.ca/executivesummary/ch36 (accessed September 22, 2014). 
7. Diabetes in Pregnancy. National Institute for Health and Clinical Excellence. http://www.nice.org.uk/proxy/?sourceUrl=http\%3a\%2f\%2fwww.nice.org.uk\%2fnicemedia\%2flive $\% 2 f 11946 \% 2 f 41342 \% 2 f$ 41342.pdf (accessed September 22, 2014)

8. Langer O, Conway DL, Berkus MD, Xenakis EM, Gonzales O. A comparison of glyburide and insulin in women with gestational diabetes. N Engl J Med. 2000;343(16):1134-1138.

9. Chmait R, Dinise T, Moore T. Prospective observational study to establish predictors of glyburide success in women with gestational diabetes mellitus. J Perinatol. 2004;24(10):617-622.

10. Conway DL, Gonzales O, Skiver D. Use of glyburide for the treatment of gestational diabetes: the San Antonio experience. J Matern Fetal Neonatal Med. 2004;15(1):51-55.

11. Jacobson GF, Ramos GA, Ching JY, Kirby RS, Ferrara A, Field DR.Comparison of glyburide and insulin for the management of gestational diabetes in a large managed care organization. Am J Obstet Gynecol. 2005;193(1):118-124.

12. Rochon M, Rand L, Roth L, Gaddipati S. Glyburide for the management of gestational diabetes: risk factors predictive of failure and associated pregnancy outcomes. Am J Obstet Gynecol. 2006;195(4):1090-1094.

13. Kahn BF, Davies JK, Lynch AM, Reynolds RM, Barbour LA. Predictors of glyburide failure in the treatment of gestational diabetes. Obstet Gynecol. 2006;107(6):1303-1309.

14. Yogev Y, Melamed N, Chen R, Nassie D, Pardo J, Hod M. Glyburide in gestational diabetes--prediction of treatment failure. J Matern Fetal Neonatal Med. 2011;24(6):842-846. doi: 10.3109/14767058.2010.531323

15. Kremer CJ, Duff P. Glyburide for the treatment of gestational diabetes. Am J Obstet Gynecol. 2004;190(5):1438-1439.

16. Cheng YW, Chung JH, Block-Kurbisch I, Inturrisi M, Caughey AB. Treatment of gestational diabetes mellitus: glyburide compared to subcutaneous insulin therapy and associated perinatal outcomes. J Matern Fetal Neonatal Med. 2012;25(4):379-384. doi: 10.3109/14767058.2011.580402

17. Tempe A, Mayanglambam RD. Glyburide as treatment option for gestational diabetes mellitus. J Obstet Gynaecol Res 2013;39(6):1147-1152. doi: 10.1111/jog.12042

18. Hellmuth E, Damm P, Mølsted-Pedersen L. Oral hypoglycaemic agents in 118 diabetic pregnancies. Diabet Med. 2000;17(7):507-511.

19. Moore LE, Briery CM, Clokey D, Martin RW, Williford NJ, Bofill JA, Morrison JC. Metformin and insulin in the management of gestational diabetes mellitus: preliminary results of a comparison. J Reprod Med. 2007;52(11):10111015.

20. Rowan JA, Hague WM, Gao W, Battin MR, Moore MP. Metformin versus insulin for the treatment of gestational diabetes. N Engl J Med. 2008;358(19):2003-15. doi: 10.1056/NEJMoa0707193

21. Tertti K, Ekblad U, Vahlberg T, Rönnemaa T. Comparison of metformin and insulin in the treatment of gestational diabetes: a retrospective, case-control study. Rev Diabet Stud. 2008;5(2):95-101. doi: 10.1900/RDS.2008.5.95

22. Balani J, Hyer SL, Rodin DA, Shehata H. Pregnancy outcomes in women with gestational diabetes treated with metformin or insulin: a case-control study. Diabet Med. 2009;26(8):798-802. doi: 10.1111/j.1464-5491.2009.02780.x

23. ljäs H, Vääräsmäki M, Morin-Papunen L, Keravuo R, Ebeling T, Saarela T, Raudaskoski T. Metformin should be considered in the treatment of gestational diabetes: a prospective randomised study. BJOG. 2011;118(7):880-885. doi: 10.1111/j.1471-0528.2010.02763.x

24. Niromanesh S, Alavi A, Sharbaf FR, Amjadi N, Moosavi S, Akbari S. Metformin compared with insulin in the management of gestational diabetes: a randomized clinical trial. Diabetes Res Clin Pract. 2012;98(3):422-9. doi: 10.1016/j.diabres.2012.09.031

25. Tertti K, Ekblad U, Koskinen $\mathrm{P}$, Vahlberg $\mathrm{T}$, Rönnemaa T. Metformin vs insulin in gestational diabetes. A randomized study characterizing metformin patients needing additional insulin. Diabetes Obes Metab. 2013;15(3):246-251. doi: 10.1111/dom.12017

26. Spaulonci CP, Bernardes LS, Trindad TC, Zugaib M, Francisco RP. Randomized trial of metformin vs insulin in the management of gestational diabetes. Am J Obstet Gynecol. 2013;209(1):34.e1-7. doi: 10.1016/j.ajog.2013.03.022

27. Silva JC, Pacheco C, Bizato J, de Souza BV, Ribeiro TE, Bertini AM. Metformin compared to glyburide for the management of gestational diabetes. Int J Gynaecol Obstet. 2010;111(1):37-40. doi: 10.1016/j.ijgo.2010.04.028

28. Moore LE, Clokey D, Pappaport V, Curet LB. Metformin compared with glyburide in gestational diabetes. Obstet Gynecol. 2010;115(1):55-59. doi: 10.1097/AOG.0b013e3181c52132

29. Silva JC, Fachin DR, Coral ML, Bertini AM. Perinatal impact of the use of metformin and glyburide for the treatment of gestational diabetes mellitus. J Perinat Med. 2012;40(3):225-228. doi: 10.1515/.jpm-2011-0175

30. Bolton S, Cleary B, Walsh J, Dempsey E, Turner MJ. Continuation of metformin in the first trimester of women with polycystic ovarian syndrome is not associated with increased perinatal morbidity. Eur J Pediatr. 2009;168(2):203-206. doi: 10.1007/s00431-008-0737-7

31. Gilbert C, Valois M, Koren G. Pregnancy outcomes after first trimester exposure to metformin: a meta analysis. Fertil Steril. 2006 Sep;86(3):658-663.

32. Metformin. Drugs in Pregnancy and Lactation, 9th edition. Briggs GG, editor. Philadelphia, PA: Lippincott Williams \& Wilkins; 2011. pages.pages 912-915.

33. Iljas $\mathrm{H}$, Vaarasmaki M, Saarela T, Keravou R, Raudaskoski T. A follow-up of randomized study of metformin and insulin in gestational diabetes mellitus: growth and development of the children at the age of 18 months. BJOG. 2014 [in press]. doi: 10.1111/1471-0528.12964

34. Coustan DR, Lowe LP, Metzger BE, Dyer AR; International Association of Diabetes and Pregnancy Study Groups. The Hyperglycemia and adverse pregnancy outcome (HAPO) study: paving the way for new diagnostic criteria for gestational diabetes mellitus. Am J Obstet Gynecol. 2010;202(6):654.e1-6. doi: 10.1016/j.ajog.2010.04.006

35. International Association of Diabetes and Pregnancy Study Groups Consensus Panel, Metzger BE, Gabbe SG, Persson B, Buchanan TA, Catalano PA, Damm P, Dyer AR, Leiva Ad, Hod M, Kitzmiler JL, Lowe LP, Mclntyre HD, Oats JJ, 
Omori Y, Schmidt MI. International association of diabetes and pregnancy study groups recommendations on the diagnosis and classification of hyperglycemia in pregnancy. Diabetes Care. 2010;33(3):676-82. doi: 10.2337/dc09-1848

36. Diagnostic Criteria and Classification of Hyperglycemia First Detected in Pregnancy. World Health Organization. http://apps.who.int/iris/bitstream/10665/85975/1/WHO NMH MND 13.2 eng.pdf (accessed September 22, 2014).

37. Acarbose. In: Drugs in Pregnancy and Lactation, 9th edition. Briggs GG, editor. Philadelphia, PA: Lippincott Williams \& Wilkins; 2011. pages 5-6.

38. Bertini AM, Silva JC, Taborda W, Becker F, Lemos Bebber FR, Zucco Viesi JM, Aquim G, Engel Ribeiro T. Perinatal outcomes and the use of oral hypoglycemic agents. J Perinat Med. 2005;33(6):519-523.

39. Sitagliptin. In: Drugs in Pregnancy and Lactation, 9th edition. Briggs GG, editor. Philadelphia, PA: Lippincott Williams \& Wilkins; 2011. pages 1337-1339.

40. Teelucksingh S, Youssef JE, Sohan K, Ramsewak S. Prolonged inadvertent pravastatin use in pregnancy. Reprod Toxicol. 2004;18(2):299-300.

41. Napoli A, Ciampa F, Colatrella A, Fallucca F. Use of repaglinide during the first weeks of pregnancy in two type 2 diabetic women. Diabetes Care. 2006;29(10):2326-2327.

42. Mollar-Puchades MA, Martin-Cortes A, Perez-Calvo A, Diaz-Garcia C. Use of repaglinide on a pregnant woment during embryogenesis. Diabetes Obes Metab. 2007;9(1):146-147.

43. Marshall V, Wilton L, Shakir S. Safety profile of repaglinide as used in general practice in England: results of a prescription-event monitoring study. Acta Diabetol. 2006;43(1):6-13. 